\title{
Isolation and characterization of novel
} microsatellite markers from Siamese fighting fish (Betta splendens, Osphronemidae, Anabantoidei) and their transferability to related species, $B$. smaragdina and $B$. imbellis

V. Chailertrit ${ }^{1,2,3}$, A. Swatdipong ${ }^{4}$, S. Peyachoknagul ${ }^{4,5}$, J. Salaenoi ${ }^{6}$ and K. Srikulnath ${ }^{1,4,5}$

${ }^{1}$ Laboratory of Animal Cytogenetics and Comparative Genomics, Department of Genetics, Faculty of Science, Kasetsart University, Bangkok, Thailand

${ }^{2}$ Center for Agricultural Biotechnology, Kasetsart University, Kamphaeng Saen Campus, Nakhon Pathom, Thailand ${ }^{3}$ Center of Excellence on Agricultural Biotechnology, Bangkok, Thailand ${ }^{4}$ Department of Genetics, Faculty of Science, Kasetsart University, Bangkok, Thailand ${ }^{5}$ Center for Advanced Studies in Tropical Natural Resources, National Research University Kasetsart University, Bangkok, Thailand

${ }^{6}$ Department of Marine Science, Faculty of Fisheries, Kasetsart University, Bangkok, Thailand

Corresponding author: K. Srikulnath

E-mail: kornsorn.s@ku.ac.th / ksrikulnath@yahoo.com

Genet. Mol. Res. 13 (3): 7157-7162 (2014)

Received March 28, 2013

Accepted September 30, 2013

Published September 5, 2014

DOI http://dx.doi.org/10.4238/2014.September.5.1

ABSTRACT. Ten novel microsatellite markers were developed and characterized from Siamese fighting fish (Betta splendens). Nine of 
ten markers were polymorphic, exhibiting an allelic number $\left(N_{\mathrm{A}}\right)$ from 2 to 6 alleles per locus. The effective number of alleles $\left(N_{\mathrm{E}}\right)$ ranged from 1.60 to 3.08 (average of 2.30). The observed $\left(H_{\mathrm{O}}\right)$ and expected $\left(H_{\mathrm{E}}\right)$ heterozygosities ranged from 0.13 to 0.67 (average of 0.39 ) and 0.29 to 0.63 (average of 0.50 ), respectively. Linkage disequilibrium was not significantly detected for any pair of loci, and only two loci (BettaMS23 and BettaMS28) showed significant deviations from Hardy-Weinberg expectations. Of these, six loci could be amplified in genomic DNA of the closely related species $B$. imbellis and three loci in B. smaragdina. These microsatellite markers could be used as a tool to investigate genetic diversity and population structure, as well as breeding programs in hatcheries.

Key words: Microsatellite; Siamese fighting fish; Betta splendens; Heterozygosity; Transferability

\section{INTRODUCTION}

The Siamese fighting fish (Betta splendens, Anabantoidei) is an ornamental fish that widely inhabits northern and central Thailand, Malaysia, Cambodia, and Vietnam. Males behaviorally build bubble nests and care for developing eggs until they reach the larval stage. Beautiful body features of Betta species, such as color and scale pattern, and body shape and fin size, make them a flourishing species in markets worldwide. However, the local population of the Siamese fighting fish has been rapidly declining because of loss of its natural habitat and contamination from artificially bred fighting fish. This issue needs serious attention in the context of biodiversity and conservation, since all wild populations of B. splendens are now critically threatened (Vidthayanon, 2011). To delineate the management of population structures in the wild and in breeding programs in hatcheries, effective and reliable methods using molecular markers such as microsatellite markers are necessary. However, Betta-specific microsatellite markers have not yet been developed for population monitoring. In this study, we report ten novel Betta splendens microsatellites markers, most of which were successfully amplified in two closely related species, B. smaragdina and B. imbellis.

\section{MATERIAL AND METHODS}

Whole genomic DNA was isolated from tail muscle tissues of a single individual using a standard phenol-chloroform protocol as previously described (Srikulnath et al., 2010). Microsatellite markers were developed following the enriched library protocol (Zane et al., 2002) with slight modification. Total genomic DNA was digested with MseI. The fragmented DNAs were ligated to specific adapters (5'-GACGATGAGTCCTGAG-3' and 5'-TACTCAGGAC TCAT-3'), and then amplified by polymerase chain reaction (PCR) using the oligo-adaptor as primer. PCR products were hybridized to eight streptavidin-biotinylated oligo simple sequence repeat (SSR) complexes: (CA $)_{15},(\mathrm{GA})_{15},(\mathrm{GC})_{10},(\mathrm{ACC})_{10},(\mathrm{CCT})_{10},(\mathrm{GAT})_{10},(\mathrm{CAG})_{10}$, and (GCT) ${ }_{10}$ with magnetic beads (Dynabeads ${ }^{\circledR}$ Myone $^{\mathrm{TM}}$ Streptavidin C1, Invitrogen, Carlsbad, CA, USA). The enriched DNAs were molecularly cloned using pGEM $^{\circledR}-\mathrm{T}$ easy Vector 
(Promega, USA) and transformed into competent E. coli DH5 $\alpha$ cells (Promega). To confirm the presence of microsatellite sequences, the positive clones were subjected to dot-blot hybridization using the SSR probes as mentioned above and a North2South ${ }^{\circledR}$ Chemiluminescent Hybridization and Detection kit (Pierce, USA).

A set of 114 positive clones were randomly selected and sequenced. The nucleotide sequence of the DNA fragments was determined (1st Base DNA sequencing service, Seri Kembangan, Malaysia) and seventy clones were discarded because of inappropriate properties, such as extremely long or short repeat stretches or SSR located close to the cloning site. The clones with sufficient flanking region were recovered and used to design the specific primers using Primer3 (Rozen and Skaletsky, 2000). The candidate SSR primers were tested for their ability to produce a readable pattern with genomic DNA of fifteen individuals of $B$. splendens collected from a population in Nakhon Pathom, Thailand $\left(13^{\circ} 45^{\prime} \mathrm{N}, 100^{\circ} 04^{\prime} \mathrm{E}\right)$. Twenty-five nanograms of genomic DNA were added to $20 \mu \mathrm{L}$ 1X PCR buffer, $1.5 \mathrm{mM} \mathrm{MgCl}, 0.2 \mathrm{mM}$ dNTPs, $5.0 \mu \mathrm{M}$ specific primers, and 0.5 U Taq DNA polymerase (Invitrogen). PCR cycling conditions consisted of an initial denaturation at $94^{\circ} \mathrm{C}$ for $5 \mathrm{~min}$, followed by 35 cycles of denaturation at $94^{\circ} \mathrm{C}$ for $30 \mathrm{~s}$, primer annealing at $50^{\circ} / 60^{\circ} \mathrm{C}$ for $30 \mathrm{~s}$, and primer extension at $72^{\circ} \mathrm{C}$ for $1 \mathrm{~min}$, and then post-cycling extension at $72^{\circ} \mathrm{C}$ for $5 \mathrm{~min}$ (Table 1 ).

The PCR products were subsequently detected on a $6 \%$ denaturing polyacrylamide gel (w/v) and visualized by silver staining as previously described (Benbouza et al., 2006). The sizes of allele were measured using the GelAnalyzer program (www.gelanalyzer.com/ index.html). The expected DNA fragments were then extracted from silver-stained gels and cloned into pGEMT-Easy Vector System I (Promega), and their nucleotide sequencing was carried out as mentioned above. Nucleotide sequences of all loci were deposited in DDBJ (DNA Data Bank of Japan, http://www.ddbj.nig.ac.jp/index-e.html).

\section{RESULTS AND DISCUSSION}

Ten SSR primer pairs were successfully amplified from genomic DNA of fifteen individuals of $B$. splendens as seen from the high quality single-banded products of the expected sizes. However, only nine markers exhibited polymorphism. These markers were then subjected to determination of the allelic number $\left(N_{\mathrm{A}}\right)$, effective number of alleles $\left(N_{\mathrm{F}}\right)$, observed heterozygosity $\left(H_{\mathrm{O}}\right)$, expected heterozygosity $\left(H_{\mathrm{E}}\right)$, Hardy-Weinberg equilibrium (HWE), and linkage disequilibrium (LD) using the GENEPOP 4.0 program (Raymond and Rousset, 1995). Thirty-five alleles were obtained from all loci. $N_{\mathrm{A}}$ ranged from 2 to 6 , and the $N_{\mathrm{E}}$ ranged from 1.60 to 3.08 (average of 2.30). In addition, $H_{\mathrm{O}}$ and $H_{\mathrm{E}}$ ranged from 0.13 to 0.67 (average of 0.39 ) and 0.29 to 0.63 (average of 0.50 ), respectively (Table 1). No evidence of significant LD was observed in any loci pair, and only two loci (BettaMS23 and BettaMS28) showed significant deviations from HWE.

Considering the specifications of behavioral and morphological characters, all nominal species of fighting fish in the genus Betta could be classified into 15 clades, one of which is the Betta splendens (bubble-nest building bettas) clade comprising B. splendens, B. smaragdina, B. imbellis and B. stiktos (Witte and Schmidt, 1992). B. smaragdina and B. imbellis are widely distributed in the northeast and south of continental Thailand, respectively, whereas $B$. stiktos inhabits Cambodia (Goldstein, 2001, Tan and Ng, 2005). Reports on molecular phylogenies of genus Betta suggest that $B$. splendens is more closely related to $B$. imbellis than to $B$. smaragdina (Ruber et al., 2004; Sriwattanarothai et al., 2010). These findings led us to predict that our SSR markers could be more transferable in B. imbellis than in B. smaragdina. 


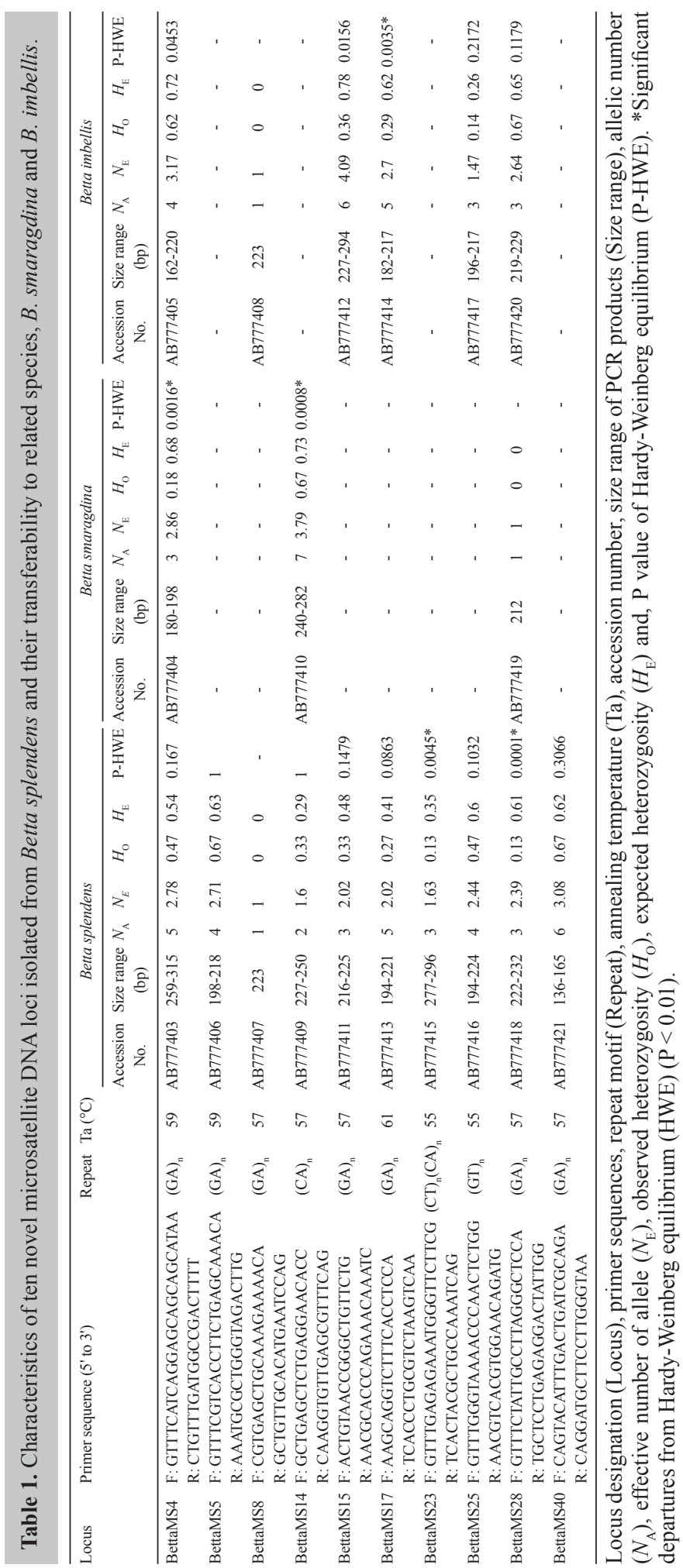


Cross-species amplification was then performed to determine the transferability of SSR markers. Fifteen individuals of each fighting fishes (B. smaragdina collected from a population in Ubon Ratchathani $\left(15^{\circ} 15^{\prime} \mathrm{N}, 104^{\circ} 50^{\prime} \mathrm{E}\right)$ and $B$. imbellis collected from a population in Trang $\left(7^{\circ} 33^{\prime} \mathrm{N}, 99^{\circ} 36^{\prime} \mathrm{E}\right)$ were used, and PCR was conducted as mentioned above. The results showed that three of ten microsatellite markers (BettaMS4, BettaMS14, and BettaMS28) were successfully amplified in $B$. smaragdina. However, only two markers exhibited polymorphism.

In total, ten alleles were obtained, with $N_{\mathrm{A}}$ ranging from 3 to 7 , and $N_{\mathrm{E}}$ ranging from 2.86 to 3.79 (average of 3.33). $H_{\mathrm{O}}$ and $H_{\mathrm{E}}$ ranged from 0.18 to 0.67 (average of 0.42 ) and 0.68 to 0.73 (average of 0.71), respectively. Six of the ten SSR markers (BettaMS4, BettaMS8, BettaMS15, BettaMS17, BettaMS25, and BettaMS28) showed cross-species amplification to $B$. imbellis. Five of the six loci, being polymorphic markers, could provide 21 alleles in $B$. imbellis, with $N_{\mathrm{A}}$ ranging from 3 to $6, N_{\mathrm{E}}$ ranging from 1.47 to 4.09 (average of 2.81). $H_{\mathrm{O}}$ and $H_{\mathrm{E}}$ were found to range from 0.14 to 0.67 (average of 0.42 ) and 0.26 to 0.78 (average of 0.61 ), respectively. Interestingly, two polymorphic markers (BettaMS4 and BettaMS28) could be amplified in the genomic DNA of all species. These results suggest that the flanking and microsatellite region of these loci may be highly conserved in the lineage of Betta splendens clade.

To the best of our knowledge, this is the first report on SSR marker transferability in the genus Betta. These markers could become a powerful tool for assessing genetic diversity and supporting conservation studies. However, several wild fighting fish populations are required to test the polymorphism of markers, and many species of Betta need to be deployed to confirm the transferability of SSR markers.

\section{ACKNOWLEDGMENTS}

Research supported by the Center of Excellence on Agricultural Biotechnology, Science and Technology Postgraduate Education and Research Development Office, Office of Higher Education Commission, Ministry of Education. (AG-BIO/PERDO-CHE) and Center for Advanced Studies in Tropical Natural Resources, National Research University-Kasetsart University, Kasetsart University, Thailand (CASTNAR, NRU-KU, Thailand).

\section{REFERENCES}

Benbouza H, Jacquemin JM, Baudoin JP and Mergeai G (2006). Optimization of a reliable, fast, cheap and sensitive silver staining method to detect SSR markers in polyacrylamide gels. Biotechnol. Agron. Soc. Environ. 10: 77-81.

Goldstein RJ (2001). Bettas A complete Pet Owner's Manual. Barron's, New York.

Raymond M and Rousset F (1995). GENEPOP (version-1.2): population genetics software for exact tests and ecumenicism. J. Hered. 86: 248-249.

Rozen S and Skaletsky HJ (2000). Primer3: Bioinformatics Methods and Protocols. Humana Press. In: Methods in Molecular Biology (Krawetz S and Misener S, eds.) New Jersey, 365-386. Available at [http://frodo.wi.mit.edu/cgibin/primer3/primer3_www.cgi]. Accessed July 15, 2013.

Ruber L, Britz R, Tan HH, Ng PK, et al. (2004). Evolution of mouthbrooding and life-history correlates in the fighting fish genus Betta. Evolution 58: 799-813.

Srikulnath K, Matsubara K, Uno Y, Thongpan A, et al. (2010). Genetic relationship of three butterfly lizard species (Leiolepis reveesii rubritaeniata, Leiolepis belliana belliana, Leiolepis boehmei, Agamidae, Squamata) inferred from nuclear gene sequence analysis. Kasetsart J. (Nat. Sci.) 44: 424-435.

Sriwattanarothai N, Steinke D, Ruenwongsa P, Hanner R, et al. (2010). Molecular and morphological evidence supports the species status of the Mahachai fighter Betta sp. Mahachai and reveals new species of Betta from Thailand. $J$. Fish. Biol. 77: 414-424. 
Tan HH and Ng PKL (2005). The fighting fishes (Teleostei: Osphronemidae: genus Betta) of Singapore, Malaysia and Brunei. Raffles Bull. Zool. 13 (Suppl 13): 43-99.

Vidthayanon C (2011). Betta splendens. In: IUCN 2012. IUCN Red List of Threatened Species. Version 2012.2. Available at [http://www.iucnredlist.org]. Accessed December 6, 2012.

Witte KE and Schmidt J (1992). Betta brownorum, a new species of anabantoids (Teleostei: Belontiidae) from northwestern Borneo, with a key to the genus. Ichthyol. Explor. Freshw. 2: 305-330.

Zane L, Bargelloni L and Patarnello T (2002). Strategies for microsatellite isolation: a review. Mol. Ecol. 11: 1-16. 